\title{
PT1b Stage Finding
}

National Cancer Institute

\section{Source}

National Cancer Institute. pT 1b Stage Finding. NCI Thesaurus. Code C48761.

A pathologic primary tumor TNM stage finding. The definition of $\mathrm{pT} 1 \mathrm{~b}$ stage finding depends on the particular type of cancer that it refers to; for example, for breast cancer, PT $1 \mathrm{~b}$ stage finding is defined as follows: cancer with tumor size more than $0.5 \mathrm{~cm}$, but not more than $1.0 \mathrm{~cm}$ in greatest dimension; for lung cancer, pT $1 \mathrm{~b}$ stage finding is defined as follows: cancer with a tumor size more than $2 \mathrm{~cm}$ but $3 \mathrm{~cm}$ or less in greatest dimension, surrounded by lung or visceral pleura and without bronchoscopic evidence of invasion more proximal than the lobar bronchus (i.e., not in the main bronchus). (from AJCC 7th Ed.) 